\title{
Competing Mortality Contributes to Excess Mortality in Patients with Poor-Risk Lymph Node-Positive Prostate Cancer Treated with Radical Prostatectomy
}

\author{
Michael Froehner ${ }^{\mathrm{a}}$ Albrecht Scholz ${ }^{\mathrm{e}}$ Rainer Koch ${ }^{\mathrm{c}}$ Oliver W. Hakenberg ${ }^{\mathrm{d}}$ \\ Gustavo B. Baretton ${ }^{b}$ Manfred P. Wirth ${ }^{a}$

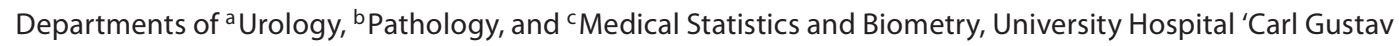 \\ Carus', Technical University of Dresden, Dresden, d Department of Urology, University of Rostock, Rostock, and \\ e Department of Urology, HELIOS Clinic Aue, Aue, Germany
}

\begin{abstract}
Key Words
Urological neoplasms $\cdot$ Prostate cancer $\cdot$ Lymph nodes •

Radical prostatectomy $\cdot$ Prognostic factors $\cdot$ Overall survival $\cdot$ Disease-specific survival $\cdot$ Competing mortality
\end{abstract}

\begin{abstract}
Background: Factors predicting survival in men with lymph node-positive prostate cancer are still poorly defined. Patients and Methods: 193 prostate cancer patients with histopathologically proven lymph node involvement with a median follow-up of 7.3 years were studied. $94 \%$ of patients received immediate hormonal therapy. Kaplan-Meier curves were calculated to evaluate overall survival rates and compared with the log-rank test. Cumulative disease-specific and competing mortality rates were calculated by competing risk analysis and compared with the Pepe-Mori test. Cox proportional hazard models were used to determine the independent significance of predictors of all-cause mortality. Results: Age (70 years or older vs. younger), Gleason score (8-10 vs. 7 or lower) and the number of involved nodes ( 3 or more vs. 1-2) were identified as independent predictors of all-cause mortality. When patients with $0-1$ of these risk factors were compared with those with 2-3 risk factors, all-
\end{abstract}

cause (rates after 10 years $21 \%$ vs. $71 \%, p<0.0001$ ), diseasespecific (12 vs. $37 \%, p=0.009$ ) and competing mortality (9 vs. $33 \%, p=0.02$ ) differed significantly. Conclusions: Some of the excess mortality in patients with poor-risk lymph node-positive prostate cancer may be attributed to increased competing mortality, possibly caused by an interaction between comorbid diseases and hormonally treated persistent or progressive prostate cancer.

Copyright $\odot 2012$ S. Karger AG, Basel

\section{Introduction}

In the Western world, prostate cancer is the most common solid organ malignancy in males [1]. In contrast to many other cancers, lymph node involvement in prostate cancer is frequently associated with long-term survival although definite cure is improbable. The prognostic factors predicting survival in men with lymph node-positive prostate cancer are still poorly defined [2]. In this study, we evaluated several tumor-related and host-related variables as potential predictors of survival in this population.

\section{KARGER}

Fax +41613061234

E-Mail karger@karger.ch

www.karger.com
(C) 2012 S. Karger AG, Basel

0042-1138/12/0892-0148\$38.00/0

Accessible online at:

www.karger.com/uin
Michael Froehner, MD

Department of Urology, University Hospital 'Carl Gustav Carus'

Technical University of Dresden

Fetscherstrasse 74, DE-01307 Dresden (Germany)

Tel. +49 351458 2447, E-Mail Michael.Froehner@uniklinikum-dresden.de 


\section{Patients and Methods}

Patient Sample

Between December 1st, 1992 and December 31st, 2005, of 2,205 patients consecutively treated by radical prostatectomy, 194 had histopathologically proven lymph node involvement and constituted the study group. Those in whom surgery was aborted after lymph node dissection were excluded. Institutional review board approval was obtained. Lymph node dissection was done along the external iliac vessels, with the bifurcation of the common iliac artery as proximal border and in the obturator fossa. The number of tumor-positive lymph nodes was available in all cases. The number of removed lymph nodes was available in $189 / 194$ patients. The mean number of removed nodes was 14 (range 4-42) in those patients. Adjuvant hormonal treatment was recommended to patients with positive lymph nodes. In 136/194 (70\%) hormonal treatment was started within 3 months of surgery; 182/194 patients (93\%) received early hormonal treatment within 1 year of surgery. $43 / 194$ patients (22\%) had had received neoadjuvant hormonal treatment prior to surgery. PSA values were considered only in patients without neoadjuvant hormonal treatment. The mean PSA in those without neoadjuvant hormonal treatment was $20.6 \mathrm{ng} / \mathrm{ml}$. One patient for whom no Gleason score was available was excluded leaving 193 patients for survival analysis. The mean age was 64.3 years. The mean follow-up in the censored patients was 8.4 years.

\section{Stratifications}

After performing an exploratory analysis with three-sided stratifications of all variables (data not shown), two-sided stratification promising maximal contrast were used for further analyses. Besides tumor-related variables, the patients were stratified by age and four comorbidity classifications (the American Society of Anesthesiologists (ASA): physical status classification [3], the New York Heart Association (NYHA) classification of cardiac insufficiency [4], the classification of angina pectoris of the Canadian Cardiovascular Society (CCS) [5] and the Charlson score [6]) (tables 1-3).

\section{Study Endpoints}

Deaths from prostate cancer (presence of uncontrolled progressive disease at the time of death), deaths from competing causes (absence of uncontrolled progressive disease at the time of death) and death from any cause were the study endpoints.

\section{Statistical Analysis}

Mantel-Haenszel hazard ratios and Kaplan-Meier overall survival curves were calculated. Comparisons were made with the log-rank test. The impact of different causes of death was analyzed by competing risk analysis [7]. The related comparisons were made with the Pepe-Mori test. All $\mathrm{p}$ values are raw values. Cox proportional hazard models were used to determine the independent significance of prognostic variables. The statistical analyses were performed with own macros for the Statistical Analysis Systems (SAS Institute, Cary, N.C., USA) statistical package.

\section{Results}

The results of the univariate analysis with overall mortality as endpoint are shown in table 1. In addition to age, numerous tumor- and comorbidity-related factors were significantly associated with overall mortality. Gleason score and tumor stage were significantly associated with disease-specific mortality whereas the number of involved nodes did not reach the significance level (table 2). Age, ASA classification and Charlson score were significantly associated with competing mortality (table 3). Using 70 years as the threshold, in the multivariate analysis, only age, Gleason score and the number of involved nodes were identified as independent predictors of overall survival. Age lost, however, its independent prognostic significance when an age threshold of 65 years was chosen (table 4). With the independent risk factors identified in the multivariate analysis with 70 years as age threshold, the patients were subdivided into risk groups with distinctly different overall and disease-specific survival rates (fig. 1,2). Comparing patients with $0-1$ versus $2-3$ risk factors, overall, diseasespecific and competing mortality differed significantly (table 5).

\section{Discussion}

In this study, the survival rates in patients with positive lymph nodes at radical prostatectomy differed widely. A sizeable minority of almost one third of patients without additional adverse prognostic factors had an excellent long-term survival rate $(90 \%$ overall and $97 \%$ disease-specific survival after 10 years; fig. 1,2). This was similar to that usually seen in patients with node-negative disease. In the most unfavorable subset comprising about $25 \%$ of node-positive patients, however, only less than $30 \%$ survived for 10 years or more after radical prostatectomy. However, even in this subgroup with poor survival only $37 \%$ of patients actually died from prostate cancer within 10 years (fig. 1, 2; table 5).

The 10-year overall (66 vs. 67\%) and disease-specific ( 82 vs. $82 \%$ ) survival rates in this study were narrowly exactly the same as in a large bi-centric series treated between 1988 and 2003 with the same mean number of removed lymph nodes $(n=14)$ [8]. Something higher survival rates (76 and $87 \%$ ) were observed in the immediate hormonal treatment arm in the randomized trial by Messing et al. [9], whereas in the deferred treatment arm (hormonal treatment at symptomatic progression) the 
Table 1. Results of the univariate analysis concerning overall mortality using two-sided stratifications

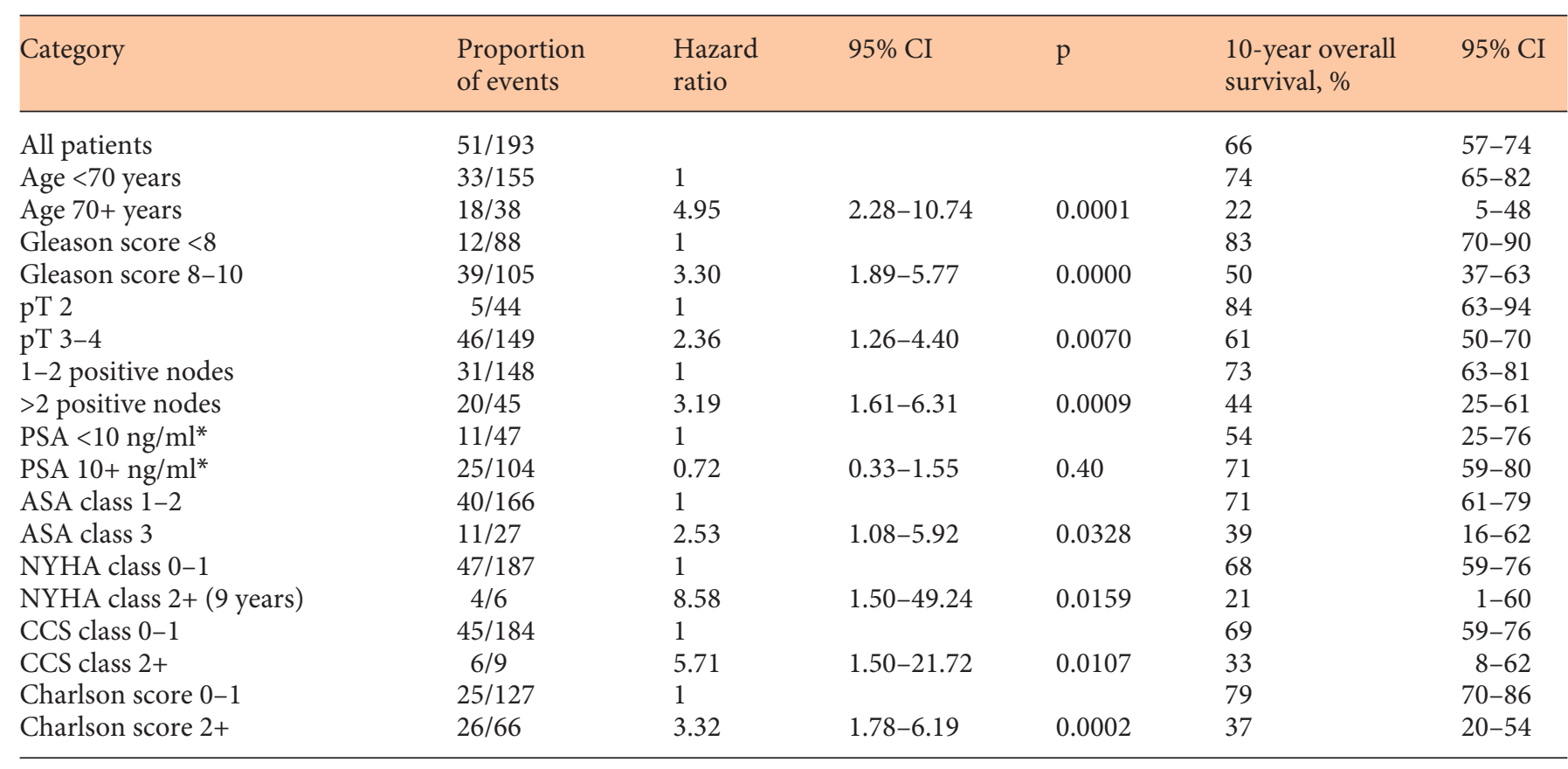

* Only those without neoadjuvant hormonal treatment.

Table 2. Results of the competing risk analyses concerning disease-specific mortality using two-sided stratifications

\begin{tabular}{|c|c|c|c|c|}
\hline Category & $\begin{array}{l}\text { Proportion } \\
\text { of events }\end{array}$ & $\begin{array}{l}10 \text {-year } \\
\text { cumulative } \\
\text { disease- } \\
\text { specific } \\
\text { mortality, \% }\end{array}$ & $95 \%$ CI & $\mathrm{p}$ \\
\hline All patients & $31 / 193$ & 18 & $12-25$ & \\
\hline Age $<70$ years & $22 / 155$ & 16 & $9-23$ & \\
\hline Age $70+$ years & $9 / 38$ & 28 & $7-50$ & 0.24 \\
\hline Gleason score $<8$ & $5 / 88$ & 5 & $1-10$ & \\
\hline Gleason score 8-10 & $26 / 105$ & 31 & $19-42$ & $<0.0001$ \\
\hline pT 2 & $2 / 44$ & 5 & $0-15$ & \\
\hline pT $3-4$ & $29 / 149$ & 22 & $14-30$ & $<0.0001$ \\
\hline 1-2 positive nodes & $20 / 148$ & 15 & $8-22$ & \\
\hline$>2$ positive nodes & $11 / 45$ & 30 & $13-47$ & 0.08 \\
\hline $\mathrm{PSA}<10 \mathrm{ng} / \mathrm{ml}^{*}$ & $9 / 47$ & 14 & $6-22$ & \\
\hline PSA $10+\mathrm{ng} / \mathrm{ml}^{*}$ & $13 / 104$ & 20 & $5-34$ & 0.11 \\
\hline ASA class $1-2$ & $12 / 166$ & 19 & $12-26$ & \\
\hline ASA class 3 & $3 / 27$ & 15 & $0-34$ & 0.46 \\
\hline NYHA class $0-1$ & $29 / 187$ & 17 & $11-24$ & \\
\hline NYHA class $2+(9$ years $)$ & $2 / 6$ & 37 & $0-56$ & 0.51 \\
\hline CCS class $0-1$ & $29 / 184$ & 18 & $11-25$ & \\
\hline CCS class $2+$ & $2 / 9$ & 22 & $0-60$ & 0.64 \\
\hline Charlson score $0-1$ & $18 / 127$ & 14 & $7-21$ & \\
\hline Charlson score 2+ & $13 / 66$ & 28 & $12-43$ & 0.18 \\
\hline
\end{tabular}

* Only those without neoadjuvant hormonal treatment.
Table 3. Results of the competing risk analyses concerning competing mortality using two-sided stratifications

\begin{tabular}{|c|c|c|c|c|}
\hline Category & $\begin{array}{l}\text { Proportion } \\
\text { of events }\end{array}$ & $\begin{array}{l}10 \text {-year } \\
\text { cumulative } \\
\text { competing } \\
\text { mortality, \% }\end{array}$ & 95\% CI & $\mathrm{p}$ \\
\hline All patients & $20 / 193$ & 15 & $9-22$ & \\
\hline Age $<70$ years & $11 / 155$ & 9 & $3-15$ & \\
\hline Age $70+$ years & $9 / 38$ & 38 & $8-69$ & 0.0319 \\
\hline Gleason score $<8$ & $7 / 88$ & 12 & $3-21$ & \\
\hline Gleason score 8-10 & $13 / 105$ & 19 & $8-30$ & 0.26 \\
\hline pT 2 & $3 / 44$ & 11 & $0-23$ & \\
\hline pT 3-4 & $17 / 149$ & 17 & $9-25$ & 0.20 \\
\hline 1-2 positive nodes & $11 / 148$ & 12 & $5-19$ & \\
\hline$>2$ positive nodes & $9 / 45$ & 26 & $8-45$ & 0.16 \\
\hline $\mathrm{PSA}<10 \mathrm{ng} / \mathrm{ml}^{*}$ & $2 / 47$ & 17 & $0-45$ & \\
\hline PSA $10+\mathrm{ng} / \mathrm{ml}^{*}$ & $12 / 104$ & 15 & $6-24$ & 0.30 \\
\hline ASA class $1-2$ & $12 / 166$ & 10 & $4-16$ & \\
\hline ASA class 3 & $8 / 27$ & 46 & $16-77$ & 0.0175 \\
\hline NYHA class $0-1$ & $18 / 187$ & 14 & $8-21$ & \\
\hline NYHA class $2+(9$ years $)$ & $2 / 6$ & 41 & $0-100$ & 0.34 \\
\hline CCS class $0-1$ & $16 / 184$ & 13 & $7-20$ & \\
\hline CCS class $2+$ & $4 / 9$ & 44 & $3-89$ & 0.09 \\
\hline Charlson score $0-1$ & $7 / 127$ & 7 & $1-12$ & \\
\hline Charlson score 2+ & $13 / 66$ & 35 & $16-54$ & 0.0078 \\
\hline
\end{tabular}


Fig. 1. Kaplan-Meier overall survival curves stratified into three different risk groups by the risk factors ( 0 risk factors: $\mathrm{n}=61 ; 1$ risk factor: $\mathrm{n}=84 ; 2-3$ risk factors: $\mathrm{n}=48$ ) identified in the multivariate analysis (log-rank tests: 0 vs. 1 risk factor: $\mathrm{p}=$ 0.0219 ; 0 vs. $2-3$ risk factors: $\mathrm{p}<0.0001$; 1 vs. $2-3$ risk factors: $p<0.0001)$. When age was disregarded as a risk factor, the resulting survival curves were somewhat less clearly separated ( $\mathrm{p}$ values ranging between $<0.0001$ and 0.06 ).

Fig. 2. Disease-specific survival (100\% minus cumulative disease-specific mortality rate; deaths from causes other than prostate cancer were considered competing events) stratified into three different risk groups by the risk factors identified in the multivariate analysis (Pepe-Mori tests: 0 vs. 1 risk factor: $\mathrm{p}=0.0098$; 0 vs. $2-3$ risk factors: $\mathrm{p}=0.0005$; 1 vs. $2-3$ risk factors: $\mathrm{p}=0.09)$. When age was disregarded as a risk factor, the resulting survival curves were somewhat less clearly separated ( $p$ values ranging between 0.0002 and 0.39 ).
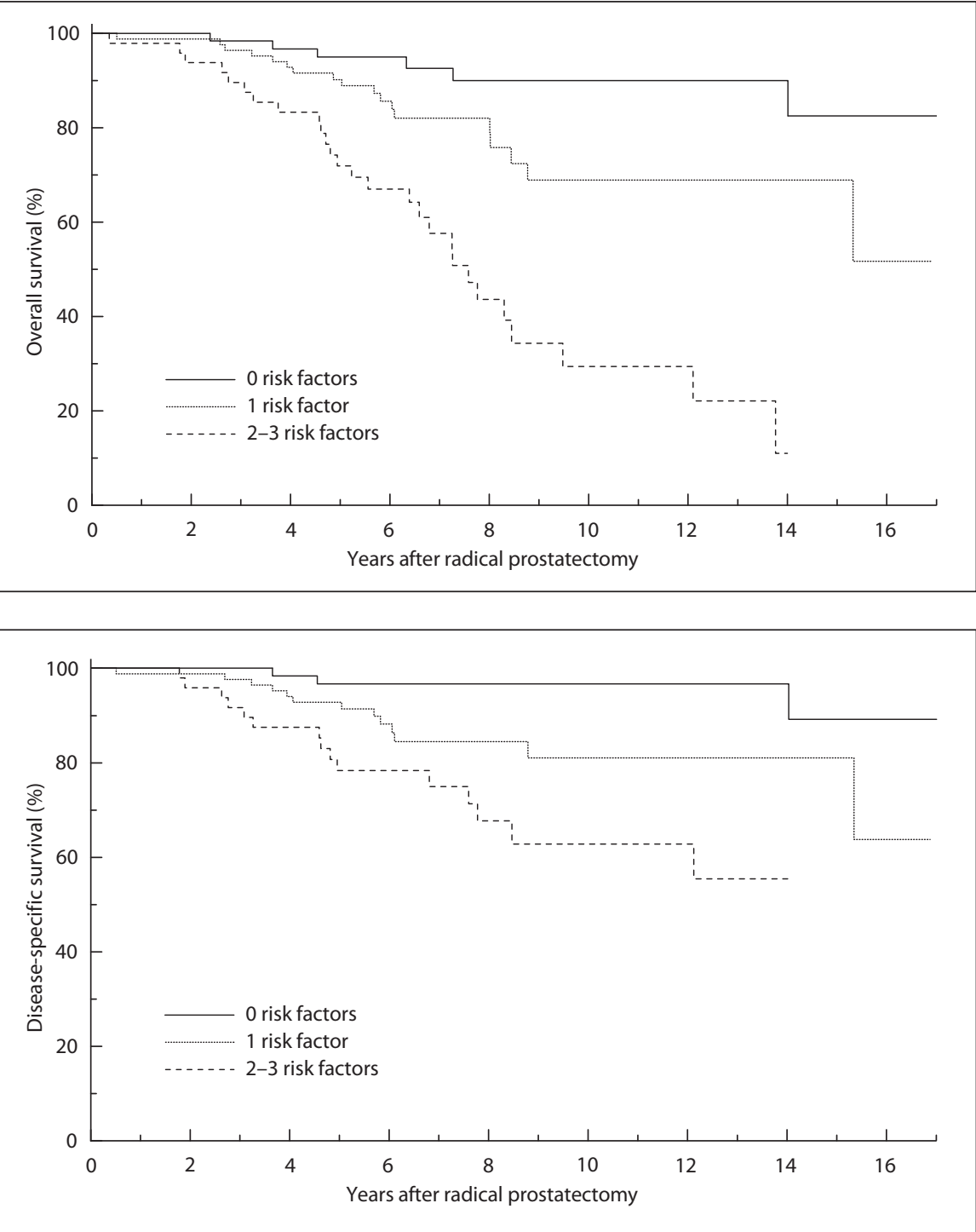

corresponding figures were clearly lower (53 and 59\%). With $60 \%$ (disease-specific survival) and 52\% (overall survival), Schumacher et al. [10] reported survival rates narrowly identical with those in the deferred treatment arm in the randomized trial of Messing et al. [9]. The authors used a comparable deferred hormonal treatment regimen but a more extended lymph node dissection with an average of 22 removed nodes [10]. Extended lymph node dissection removing about $50 \%$ more lymph nodes [10] may be supposed to include more patients with low volume lymph node involvement. The impaired survival rate in the cited study [10] compared to the early treatment arm of the trial of Messing et al. [9] and the current study suggests that early (adjuvant) hormonal treatment has a greater impact on the outcome of lymph node-positive disease after radical prostatectomy than the number of removed nodes.

This study confirms the prognostic significance of the threshold of 2 involved lymph nodes found by others [8, $10]$. In agreement with these other studies $[8,10]$, in our series, there was no significant difference between patients with 1 and 2 positive nodes (HR 1.41, 95\% CI $0.63-$ $3.16, \mathrm{p}=0.41$ in univariate analysis). The Gleason score of the prostatectomy specimen was an independent prognostic factor identified in this (table 3 ) as well as in several other studies [10-12], whereas other authors did not find independent prognostic significance of the Gleason score in node-positive patients $[2,13]$. 
Table 4. Cox proportional hazard models identifying independent predictors of overall survival in patients with lymph node-positive prostate cancer

\begin{tabular}{llll}
\hline Category & Hazard ratio & $95 \%$ CI & p \\
\hline Model with 70 years as age threshold & & & \\
Age 70+ years versus younger & 2.99 & $1.65-5.42$ & 0.0003 \\
Gleason score 8-10 versus lower & 3.14 & $1.60-6.16$ & 0.0008 \\
3 or more positive nodes versus 1-2 & 2.00 & $1.12-3.56$ & 0.0193 \\
\hline Model with 65 years as age threshold & & & \\
Gleason score 8-10 versus lower & 3.18 & $1.63-6.22$ & 0.0007 \\
3 or more positive nodes versus 1-2 & 2.26 & $1.27-4.03$ & 0.0055 \\
\hline
\end{tabular}

Using an age threshold of 65 years instead of 70 years eliminated age as an independent predictor of overall survival. With 65 years as threshold, already in the univariate analysis there was no detectable association between age and overall survival (HR 1.49, 95\% CI 0.86-2.61, $\mathrm{p}=0.16$ ).

Table 5. Overall prostate cancer-specific and competing mortality in patients with $0-1$ compared with patients with $2-3$ of risk factors (Gleason score $8-10,>2$ positive nodes and age $\geq 70$ years)

\begin{tabular}{|c|c|c|c|c|c|c|}
\hline \multirow[t]{2}{*}{ Category } & \multicolumn{6}{|c|}{ Cumulative mortality rate at 10 years } \\
\hline & $\begin{array}{l}\text { All causes } \\
\%\end{array}$ & $\mathrm{p}^{*}$ & $\begin{array}{l}\text { Prostate } \\
\text { cancer, \% }\end{array}$ & $\mathrm{p}^{* *}$ & $\begin{array}{l}\text { Competing } \\
\text { causes, } \%\end{array}$ & $\mathrm{p}^{* *}$ \\
\hline $0-1$ risk factor $(\mathrm{n}=145)$ & 21 & & 12 & & 9 & \\
\hline $95 \% \mathrm{CI}$ & $14-31$ & & $6-18$ & & $3-15$ & \\
\hline $2-3$ risk factors $(n=48)$ & 71 & $<0.0001$ & 37 & 0.0090 & 33 & 0.0210 \\
\hline $95 \% \mathrm{CI}$ & $53-86$ & & $18-56$ & & $14-53$ & \\
\hline
\end{tabular}

When age was disregarded as a risk factor and patients with $0-1$ were compared with those with 2 risk factors, the survival differences were less clear (overall survival: 88 vs. 52\%, p < 0.0001; prostate cancer-specific mortality: 15 vs. $36 \%, p=0.06$; competing mortality: 13 vs. $27 \%, \mathrm{p}=0.22) .{ }^{*}$ log-rank test, ${ }^{* *}$ Pepe-Mori test.

The role of age as a prognostic factor in patients with positive lymph nodes in this study is difficult to interpret. Whereas with a threshold of 70 years, age was a strong independent predictor of overall survival, this was no longer the case when a threshold of 65 years was chosen (table 4). An acceptance of higher comorbidity in men over 70 years referred for radical treatment with particularly unfavorable tumor-related risk factors could be a possible explanation of this phenomenon that vanished when the elderly subgroup is diluted by less strictly selected younger patients.

Whereas, generally, after radical prostatectomy competing mortality clearly outweighs prostate cancer-specific mortality [14], in lymph node-positive patients the proportion of disease-specific mortality is higher [15]. In the current study, with 18\% disease-specific and 15\% competing mortality (tables 1,2), this difference was, however, moderate. In contrast, in a recently published large multicentric study, disease-specific mortality superseded competing mortality at 10 years by $67-540 \%$ [15]. With 10-year survival differences between low-risk and high-risk groups of $32-47 \%$ (table 1), the prognostic impact of comorbidity in the univariate analysis in this study with lymph node-positive patients was clearly higher than seen after radical prostatectomy in general. In a radical prostatectomy series from the pre-PSA era, there was only a $22 \% 10$-year overall survival difference between the Charlson score classes 0 and 2 or higher [16]. In more recent studies, this difference was even lower with only $7-12 \%[17,18]$. In our series, both comorbidity and tumor-related variables seemed to be associated with the other endpoint to some extent (tables 2,3). Since none 
of the trends did reach the significance level, these small differences could be ignored. It may, however, be conceivable that there was some interaction between adverse tumor-related parameters and serious comorbidity resulting in particularly high mortality rates from both causes combined. Survival in progressive prostate cancer disease may well be negatively influenced by serious concomitant benign diseases and, conversely, progressive prostate cancer might have overproportionally increased mortality in patients with serious comorbidity. The finding of increased mortality both from prostate cancer and from competing causes in patients with $2-3$ risk factors (table 5) possibly supports this hypothesis. Since almost all patients in this sample received hormonal treatment, an aggravating effect of hormone ablation on preexisting comorbid conditions [19] may also be taken into consideration.

Altogether, the outcome of lymph node-positive patients was more heterogeneous than that of the general radical prostatectomy population. In the latter, in one large series, the overall survival rates ranged between $70 \%$ (positive nodes, age 70-79 years) and 98\% (Gleason score 6 , age $<60$ years) [15]. In contrast, in patients with positive lymph nodes in our study, the difference between the most (Gleason score $<8,<3$ positive nodes, $<70$ years, $90 \% 10$-year overall survival) and the least favorable groups (2-3 of the risk factors Gleason score 8-10, 3 or more positive nodes, 70 years or older, $29 \% 10$-year overall survival; fig. 1) was clearly higher. The wide prognostic spectrum of lymph node-positive prostate cancer should be taken into consideration when different treatment options (for instance radical prostatectomy or adjuvant radiotherapy) are compared. Even minor differences in the selection of good risks into the active treatment arms might result in outcome differences. The overall survival curve of the least favorable subset of patients in this study (fig. 1) was narrowly congruent to that observed in patients in whom radical prostatectomy was aborted because of positive lymph nodes [20]. In contrast, the most favorable subset had a higher survival probability than lymph node-positive patients receiving adjuvant radiotherapy [21]. Although efforts have been undertaken to control for possible selection effects [20,21], uncertainties remain. It seems questionable whether it will possible to reliably evaluate more aggressive treatment strategies (which are most likely to be offered to patients with favorable risk factors) for node-positive disease without performing randomized trials. Several clinically meaningful questions deserve further investigation in randomized trials in this patient population, such as timing and duration of hormonal therapy, the role of radical prostatectomy in men with gross lymph node involvement and that of adjuvant radiotherapy.

This study has several limitations. The cause of death was determined by clinical judgment and not by autopsy. Due to the retrospective setting, there was no uniform follow-up regimen and it was not possible to reliably determine postoperative treatment details other than the timing of commencement of hormonal treatment and endpoints other than mortality. $22 \%$ of patients had received neoadjuvant hormonal treatment which can lead to false Gleason score upgrading [22]. We checked whether this effect was of relevance in this study and found no overall survival differences between patients with a Gleason score of 8-10 with and without neoadjuvant hormonal therapy (10-year survival $49.1 \%$ in patients with vs. $53.1 \%$ in patients without neoadjuvant hormonal therapy, HR 1.14, 95\% CI 0.55-2.34, $\mathrm{p}=0.73$ ). Thus, it is unlikely that neoadjuvant hormonal therapy did impair the prognostic validity of the Gleason score in this sample. Therefore, we decided not to exclude patients with neoadjuvant hormonal treatment from analysis.

\section{Conclusion}

Some of the excess mortality in patients with poor-risk lymph node-positive prostate cancer (those with 2-3 of the risk factors age 70 years or older, Gleason score 8 or higher or more than 2 involved lymph nodes) may be attributed to increased competing mortality. Interaction between comorbid diseases and hormonally treated persistent or progressive prostate cancer may be discussed as a possible explanation for this observation.

\section{Disclosure Statement}

The authors declare no conflicts of interest related to the matter discussed in this article. 


\section{References}

1 Siegel R, Ward E, Brawley O, Jemal A: Cancer statistics. The impact of eliminating socioeconomic and racial disparities on premature cancer deaths. CA Cancer J Clin 2011; 61:212-236.

2 Fleischmann A, Rocha C, Saxer-Sekulic N, Zlobec I, Sauter G, Thalmann GN: High CD10 expression in lymph node metastases from surgically treated prostate cancer independently predicts early death. Virchows Arch 2011;458:741-748.

3 American Society of Anesthesiologists: ASA physical status classification system. Available from: http://www.asahq.org/clinical/ physicalstatus.htm (accessed February 19, 2012).

4 The Criteria Committee of the New York Heart Association: Nomenclature and Criteria for Diagnosis of Diseases of the Heart and Great Vessels, ed 9. Boston, Little, Brown, 1994, pp 253-256.

5 Canadian Cardiovascular Society: Canadian Cardiovascular Society grading of angina pectoris. Available from: http://www.ccs.ca/ download/position_statements/Grading\%20of\%20Angina.pdf (accessed February 19,2012 ).

6 Charlson ME, Pompei P, Ales KL, MacKenzie CR: A new method of classifying prognostic comorbidity in longitudinal studies: development and validation. J Chron Dis 1987;40:373-383

7 Pintilie M: Competing Risks: A Practical Perspective. Chichester, Wiley, 2006, pp 195-207.

8 Briganti A, Karnes JR, Da Pozzo LF, Cozzarini C, Gallina A, Suardi N: Two positive nodes represent a significant cut-off value for cancer specific survival in patients with node-positive prostate cancer. A new proposal based on a two-institution experience on 703 consecutive $\mathrm{N}+$ patients treated with radical prostatectomy, extended pelvic lymph node dissection and adjuvant therapy. Eur Urol 2009;55:261-270.
9 Messing EM, Manola J, Yao J, Kiernan M, Crawford D, Wilding G, di'SantAgnese PA, Trump D, Eastern Cooperative Oncology Group Study EST 3886: Immediate versus deferred androgen deprivation treatment in patients with node-positive prostate cancer after radical prostatectomy and pelvic lymphadenectomy. Lancet Oncol 2006;7: 472-479.

10 Schumacher MC, Burkhard FC, Thalmann GN, Fleischmann A, Studer UE: Good outcome for patients with few lymph node metastases after radical retropubic prostatectomy. Eur Urol 2008;54:344-352.

11 Da Pozzo LF, Cozzarini C, Briganti A, Suardi N, Salonia A, Bertini R: Long-term follow-up of patients with prostate cancer and nodal metastases treated by pelvic lymphadenectomy and radical prostatectomy: the positive impact of adjuvant radiotherapy. Eur Urol 2009;55:1003-1011.

12 Fleischmann A, Schobinger S, Schumacher M, Thalmann GN, Studer UE: Survival in surgically treated, nodal positive prostate cancer patients is predicted by histopathological characteristics of the primary tumor and its lymph node metastases. Prostate 2009;69:352-362.

13 Steuber T, Budäus L, Walz J, Zorn KC, Schlomm T, Chun F, Ahyai S, Fisch M, Sauter G, Huland H, Graefen M, Haese A: Radical prostatectomy improves progression-free and cancer-specific survival in men with lymph node positive prostate cancer in the prostate-specific antigen era: a confirmatory study. BJU Int 2010;107:1755-1761.

14 Stephenson AJ, Kattan MW, Eastham JA, Bianco FJ Jr, Yossepowitch O, Vickers AJ, et al: Prostate cancer-specific mortality after radical prostatectomy for patients treated in the prostate-specific antigen era. J Clin Oncol 2009;27:4300-4305

15 Eggener SE, Scardino PT, Walsh PC, Han M, Partin AW, Trock BJ, Feng Z, Wood DP, Eastham JA, Yossepowitch O, Rabah DM, Kattan MW, Yu C, Klein EA, Stephenson AJ: Predicting 15-year prostate cancer specific mortality after radical prostatectomy. J Urol 2011;185:869-875.
16 Barry MJ, Albertsen PC, Bagshaw MA, Blute ML, Cox R, Middleton RG, Gleason DF, Zincke H, Bergstralh EJ, Jacobsen SJ: Outcomes for men with clinically nonmetastatic prostate carcinoma managed with radical prostatectomy, external beam radiotherapy, or expectant management: a retrospective analysis. Cancer 2001;91:2302-2314.

17 Guzzo TJ, Dluzniewski P, Orosco R, Platz EA, Partin AW, Han M: Prediction of mortality after radical prostatectomy by Charlson comorbidity index. Urology 2010;76: 553-558.

18 Froehner M, Koch R, Litz RJ, et al: Re: Guzzo et al.: prediction of mortality after radical prostatectomy by Charlson comorbidity index. (Urology 2012;76:553-557). Urology 2010;76:1522.

19 D'Amico AV, Chen MH, Renshaw AA, Loffredo M, Kantoff PW: Androgen suppression and radiation vs radiation alone for prostate cancer. A randomized trial. JAMA 2008;299: 289-295.

20 Engel J, Bastian PJ, Baur H, Chaussy C, Gschwend JE, Oberneder R: Survival benefit of radical prostatectomy in lymph node-positive patients with prostate cancer. Eur Urol 2010;57:754-761.

21 Briganti A, Karnes RJ, Da Pozzo LF, Cozzarini C, Capitanio U, Gallina A, Suardi N, Bianchi M, Tutolo M, Salonia A, Di Muzio N, Rigatti P, Montorsi F, Blute M: Combination of adjuvant hormonal and radiation therapy significantly prolongs survival of patients with pT2-4 pN+ prostate cancer: Results of a matched analysis. Eur Urol 2011;59:832-840.

22 Bullock MJ, Srigley JR, Klotz LH, Goldenberg SL: Pathologic effects of neoadjuvant cyproterone acetate on nonneoplastic prostate, prostatic intraepithelial neoplasia, and adenocarcinoma. A detailed analysis of radical prostatectomy specimens from a randomized trial. Am J Surg Pathol 2002;26: 1400-1413. 